\title{
Avaliação topográfica e in vitro de superfícies de titânio revestidas com vidro bioativo
}

\author{
Topographic and in vitro evaluation of titanium surfaces coated with bioative glass
}

\author{
Vinícius Magalhães BARROSa, Leonardo Franchini Pan MARTINEZ $Z^{\mathrm{b}}$, Marcos Augusto de SÁc, \\ Walison Arthuso VASCONCELLOS ${ }^{\mathrm{b}}$, Allyson Nogueira MOREIRA ${ }^{\mathrm{b} *}$
}

\author{
${ }^{a}$ PUC Minas - Pontifícia Universidade Católica de Minas Gerais, Departamento de Odontologia, \\ Belo Horizonte, MG, Brasil \\ 'UFMG - Universidade Federal de Minas Gerais, Faculdade de Odontologia, Belo Horizonte, MG, Brasil \\ 'UFMG - Universidade Federal de Minas Gerais, Instituto de Ciências Biológicas, Belo Horizonte, MG, Brasil
}

\begin{abstract}
Resumo
Objetivo: Avaliar e comparar a rugosidade superficial e a atividade dos osteoblastos em contato com uma nova superfície bioativa e nanoestruturada de titânio grau 4 revestida com vidro bioativo contendo fosfato de cálcio, sintetizada pelo método sol-gel. Material e método: Sessenta e três discos de titânio, medindo $4 \mathrm{~mm}$ de diâmetro por $2 \mathrm{~mm}$ de altura, foram preparados e divididos em três grupos: microtexturizado (Ticp - controle); revestido com vidro bioativo e seco a vácuo a $37^{\circ} \mathrm{C}$ por 10 dias (BGTi37), e revestido com vidro bioativo e aquecido a $600{ }^{\circ} \mathrm{C}$ por cinco horas (BGTi600). Três espécimes de cada grupo foram utilizados para avaliação da topografia superficial e 18 espécimes, para cultura celular. Resultado: $\mathrm{O}$ revestimento de vidro bioativo diminuiu a rugosidade média quando comparado ao titânio microtexturizado. A proporção de células viáveis, a produção de fosfatase alcalina e o grau de mineralização da matriz óssea em contato com os espécimes de titânio do grupo BGTi600 foram significativamente menores em relação aos grupos controle e do titânio microtexturizado. Conclusão: Apesar de sua marcante menor rugosidade, a superfície BGTi37 apresentou comportamento biológico semelhante a uma superfície de titânio microtexturizada e moderadamente rugosa. A outra superfície experimental (BGTi600), a de menor rugosidade entre todas as testadas, apresentou os piores resultados de ativação dos osteoblastos.
\end{abstract}

Descritores: Implantes dentários; osseointegração; teste de materiais.

\begin{abstract}
Objective: To evaluate and compare the surface roughness and the activity of the osteoblasts in contact with a new bioactive and nanostructured surface of grade 4 titanium coated with bioactive glass containing calcium phosphate synthesized by the sol-gel method. Material and method: Sixty-three titanium disks, measuring $4 \times 2 \mathrm{~mm}$, were prepared and divided into three groups: rough surface, obtained by sandblasted, large-grit, acid-etched (SLA) treatment (Ticp); SLA surface coated with bioglass and dried in a vacuum at $37^{\circ} \mathrm{C}$ for 10 days (BGTi37) and SLA surface coated with bioglass and dried in air at $600{ }^{\circ} \mathrm{C}$ for 5 hours (BGTi600). Three specimens of each group were used for evaluation of surface topography and 18 for cell cultures. Result: The bioactive glass coating decreased the average roughness when compared to rough titanium surface. The proportion of viable cells, the production of alkaline phosphatase and the degree of mineralization of the bone matrix in contact with the titanium specimens of the BGTi600 group was significantly lower in relation to the control and rough titanium surface groups. Conclusion: Despite its marked lower roughness, BGTi37 surface presented a similar biological behavior to a titanium rough surface obtained by SLA treatment. The other experimental surface (BGTi600), the one with the least roughness among all tested, presented the worst results of osteoblast activation.
\end{abstract}

Descriptors: Dental implants; osseointegration; materials testing.

INTRODUÇÃO

Um grande número de implantes de titânio (Ti) é utilizado rotineiramente em cirurgias ortopédicas e odontológicas. Algumas características, como seu excelente comportamento biológico e mecânico, e sua resistência à corrosão sob condições fisiológicas, justificam a escolha do titânio comercialmente puro ou suas ligas (Ti-6Al-4V) para esta finalidade. Sua biocompatibilidade e resposta 
favorável ao fenômeno da osseointegração também justificam a larga utilização em implantes dentários ${ }^{1}$. A superfície do implante é a primeira parte a interagir com o hospedeiro, portanto suas propriedades destacam-se como um dos seis mais importantes fatores para sua incorporação ao tecido ósseo.

Como o titânio é um material biocompatível, sem capacidade de ligar-se quimicamente ao tecido ósseo e de gerar estímulos favoráveis rápidos, modificar a superfície dos implantes de titânio é desejável para melhorar suas propriedades osteoindutoras ${ }^{2}$ e acelerar a osseointegração ${ }^{3}$.

Implantes com características topográficas e físico-químicas melhoradas proporcionam um ambiente adequado, em que o potencial biológico natural para a regeneração óssea poderá ser estimulado e maximizado. Esta estratégia terapêutica pode finalmente reforçar o processo de osseointegração de implantes dentários para o seu carregamento imediato e sucesso em longo prazo ${ }^{4}$.

Dentre as modificações das superfícies dos implantes, destacam-se os recobrimentos bioativos contendo fosfato de cálcio, altamente biocompatíveis e com grande capacidade osteoindutora ${ }^{2,5-7}$. Esses revestimentos podem acelerar a osseointegração, proporcionando sítios ativos de nucleação que facilitam o crescimento dos cristais na superfície do substrato ${ }^{8,9}$, promovendo a estimulação química de células por meio de receptores de detecção de cálcio e melhorando a angiogênese, essencial para a reparação e regeneração de tecidos ${ }^{10-12}$.

Assim como a composição química da superfície dos implantes, a sua topografia superficial também é capaz de influenciar a proliferação, diferenciação, ativação e morfologia celulares, bem como a produção de matriz extracelular. Atualmente, implantes de titânio com superfícies microtexturizadas produzidas por jateamento seguido por erosão ácida predominam no mercado mundial e apresentam altas taxas de sobrevivência $(98,8)$ e de sucesso (97\%), após período de acompanhamento de 10 anos $^{13,14}$.

Os dados disponíveis na literatura científica apontam que os revestimentos bioativos contendo fosfato de cálcio melhoram a bioatividade dos implantes, porém a ausência de padronização dos procedimentos e equipamentos para a produção desses revestimentos resulta em rugosidades e composições químicas variadas, interferindo diretamente nessa propriedade. Dessa forma, o presente estudo in vitro testou uma nova superfície experimental bioativa e nanoestruturada de titânio grau 4, revestida com vidro bioativo do sistema $\left(\mathrm{SiO}_{2}\right)_{0,80}\left(\mathrm{P}_{2} \mathrm{O}_{5}\right)_{0,04}(\mathrm{CaO})_{0,16}$, sintetizada pelo método sol-gel.

A hipótese testada é a de que o revestimento com vidro bioativo contendo fosfato de cálcio é capaz de promover maior ativação dos osteoblastos quando comparado a uma superfície controle de titânio microtexturizada.

\section{MATERIAL E MÉTODO}

\section{Produção das Superfícies Experimentais}

Para a realização do presente estudo, 63 discos de uma liga de titânio grau 4, medindo $4 \mathrm{~mm}$ de diâmetro por $2 \mathrm{~mm}$ de altura, foram preparados pela empresa PecLab (Belo Horizonte, Minas Gerais, Brasil). Uma das superfícies planas desses discos foi submetida ao tratamento comercialmente utilizado pela empresa para produção de uma superfície de titânio grau 4 microtexturizada. O processo é segredo comercial da empresa e inclui o jateamento das peças com alumina e erosão ácida com solução de ácido nítrico e ácido fluorídrico, seguindo a norma ASTM B600 ${ }^{15}$.

Em seguida, todos os espécimes foram lavados igualmente sob agitação com água destilada por 10 vezes, para a remoção de resíduos e, em seguida, lavados cinco vezes com acetona. Vinte e um espécimes foram separados e constituíram o grupo controle denominado titânio microtexturizado (Ticp). Posteriormente, a solução sol-gel do vidro bioativo foi preparada. O sistema $\left(\mathrm{SiO}_{2}\right)_{0,80}\left(\mathrm{P}_{2} \mathrm{O}_{5}\right)_{0,04}(\mathrm{CaO})_{0,16}$ foi sintetizado pela hidrólise do tetraetilortosilicato (TEOS), trifenilfosfato (PACK) e CaCl $2 \cdot 2 \mathrm{H}_{2} \mathrm{O}$, catalisada por ácido, a uma temperatura entre 24 e $26^{\circ} \mathrm{C}$, e com umidade relativa inferior a 59\%. Para formação do vidro bioativo, foram adicionados, a uma solução alcoólica, catalisado por ácido ( $\mathrm{pH} 1,5)$, o TEOS, o PACK e o $\mathrm{CaCl}_{2} \cdot 2 \mathrm{H}_{2} \mathrm{O}$, em intervalos de 15 minutos, sob constante agitação. Após a completa solubilização do sal hidratado, a solução foi agitada por mais 10 minutos $^{16}$.

O recobrimento dos demais 42 espécimes foi obtido pela imersão nessa solução, com ângulo de imersão e retirada de 90 graus e velocidade de remoção de $1,05( \pm 0,02) \mathrm{cm} \cdot \mathrm{min}^{-1}$. Após o processo de imersão, as peças foram expostas ao ar por 30 minutos, em ambiente com temperatura de $30^{\circ} \mathrm{C}$. Posteriormente, os 42 espécimes foram divididos em dois grupos com diferentes tratamentos térmicos. O primeiro grupo (BGTi37) foi seco a vácuo, a $37^{\circ} \mathrm{C}$, por 10 dias. O segundo grupo (BGTi600) foi aquecido a $600^{\circ} \mathrm{C}$ por cinco horas. Ao final desse processo, foram obtidos 21 espécimes para cada um dos dois grupos experimentais: liga de titânio grau 4 revestida com vidro bioativo contendo fosfato de cálcio e seco a $37{ }^{\circ} \mathrm{C}$ (BGTi37) e liga de titânio grau 4 revestida com vidro bioativo contendo fosfato de cálcio e seco a $600{ }^{\circ} \mathrm{C}$ (BGTi600). A síntese, assim como o revestimento, foram realizados no Departamento de Química da UFMG, também descrito em De Oliveira (2015) 27.

Dos 21 espécimes de cada grupo, três foram utilizados para avaliação da topografia superficial e 18 para os ensaios celulares de viabilidade celular, produção de fosfatase alcalina e mineralização.

\section{Avaliação Topográfica das Superfícies}

A topografia superficial do grupo controle e dos dois grupos experimentais foi analisada em triplicata por microscopia de força atômica, utilizando o microscópio MFP-3D-SA (Asylum Research, Santa Bárbara, Califórnia, EUA) com sonda AC160TS-R3 [ $\mathrm{k}=26(11-54) \mathrm{N} / \mathrm{m}(\mathrm{k}=$ constante elástica $)]$, frequência de ressonância de $300(200-400) \mathrm{kHz}$ e o modo de análise tapping. Após a inspeção de toda a superfície do disco e considerando a homogeneidade dos revestimentos, duas imagens de $100 \mu \mathrm{m}^{2}$ cada foram obtidas de cada espécime. Após a obtenção das imagens, sua rugosidade foi aferida, sem qualquer correção ou manipulação, utilizando-se o programa AR 14.16.136 (Asylum Research, Santa Bárbara, Califórnia, EUA). Os parâmetros utilizados para avaliação da rugosidade foram a rugosidade quadrática média (Sq) e a rugosidade aritmética $(\mathrm{Sa})^{17}$. 


\section{Avaliação in vitro das Superfícies}

Para o estudo experimental in vitro, aprovado pela comissão de ética no uso de animais sob o Protocolo 350/2013, células osteoblásticas primárias foram extraídas de calvária de ratos Wistar neonatos entre dois e quatro dias de vida, pelo método de digestão sequencial enzimática utilizando colagenase e tripsina ${ }^{18}$.

As células extraídas foram incubadas em meio a-MEM completo suplementado com $10 \%$ de soro fetal bovino (Gibco, Carlsbad, Califórnia, EUA), $100 \mu \mathrm{g} / \mathrm{mL}$ de gentamicina, $1 \%$ de antimicótico e de solução de ácido ascórbico $(5 \mu \mathrm{g} / \mathrm{mL})$ (Sigma-Aldrich, Saint Louis, Missouri, EUA) e betaglicerofosfato $\left(2,16 \mathrm{mg} / \mathrm{mL}\right.$ ) (Sigma-Aldrich, Saint Louis, Missouri, EUA) a $37^{\circ} \mathrm{C}$, em estufa (Heal Force 160W, Heal Force Bio-Meditech Holdings Limited, Xangai, China) com atmosfera úmida contendo $5 \%$ de $\mathrm{CO}_{2}$. O meio de cultura foi trocado a cada dois dias. As culturas foram monitoradas diariamente em microscópio óptico invertido (MoticAE31, Ted Pella Incorporation, Redding, California, EUA). Após três dias, a confluência celular entre 70 e $80 \%$ já podia ser observada. As culturas foram então expandidas utilizando tripsina a $0,25 \%$. Após atingirem novamente a confluência, o processo de expansão foi repetido até a terceira passagem. Os discos de titânio dos grupos Ticp, BGTi37 e BGTi600 foram distribuídos em sextuplicatas nas microplacas de 96 poços, para os experimentos de viabilidade (MTT) e atividade celular (produção de fosfatase alcalina e vermelho de alizarina). Em todos os experimentos, os osteoblastos foram plaqueados na densidade de $3,0 \times 10^{3}$ células/poço, diretamente sobre o poço (controle absoluto, ou seja, na ausência de qualquer material) ou sobre as superfícies tratadas dos discos de titânio ( $n=6 /$ grupo) e cultivados por sete ou 14 dias, dependendo do ensaio. Após o plaqueamento, as microplacas foram incubadas em estufa a $37^{\circ} \mathrm{C}$ com atmosfera úmida com $5 \%$ de $\mathrm{CO}_{2}$. O meio de cultura foi trocado a cada dois dias.

O ensaio de viabilidade celular utilizando-se MTT (Sigma-Aldrich, Saint Louis, Missouri, EUA) foi realizado após sete dias de cultivo celular. O MTT foi preparado na concentração de $10 \mathrm{mg} / \mathrm{mL}$, segundo Mosman $^{19}$. A produção da fosfatase alcalina foi analisada pelo ensaio de 5-bromo,4-chloro,3-indolylphosphate-nitrobluetetrazolium (BCIP-NBT) (Invitrogen, Carlsbad, Califórnia, USA), conforme previamente descrito, após sete dias de cultura celular ${ }^{20}$. Para o ensaio de mineralização com vermelho de alizarina, o protocolo utilizado foi o proposto por Lin et al. ${ }^{21}$, após 14 dias de cultura.

\section{Análise Estatística}

Os dados de rugosidade superficial, viabilidade celular, produção da fosfatase alcalina e mineralização foram analisados com auxílio do programa GraphpadPrism versão 5, com nível de significância de 5\%. A distribuição normal dos dados foi comprovada pelo Teste de Shapiro-Wilk. O princípio da homocedasticidade foi confirmado e os dados foram submetidos à análise de variância (ANOVA), seguida pelo Teste de Tukey, com nível de significância de 5\%.

\section{RESULTADO}

Imagens topográficas tridimensionais das três diferentes superfícies (Ticp, BGTi37 e BGTi600) foram obtidas por microscopia de força atômica, com campos de varredura de $10 \times 10 \mu \mathrm{m}^{2}$ (Figura 1).

A comparação das rugosidades superficiais dos três grupos pode ser visualizada na Figura 2.

O revestimento de vidro bioativo diminuiu a rugosidade média quando comparada à do titânio puro, sendo esse grupo o de maior rugosidade média e o grupo BGTi600 o de menor rugosidade.

Os dados do teste de viabilidade dos osteoblastos, avaliada pelo ensaio de MTT, e da produção de fosfatase alcalina podem ser visualizados no gráfico após sete dias de cultura. O grau de mineralização da matriz óssea foi avaliado pelo ensaio vermelho de alizarina após 14 dias de cultura e também pode ser observado no gráfico a seguir (Figura 3).

A proporção de células viáveis em contato com os espécimes de titânio do grupo BGTi600 foi significativamente menor em relação aos grupos controle e do titânio microtexturizado (Ticp). A proporção de células viáveis do grupo experimental BGTi600 não foi significativamente diferente quando comparada ao outro grupo experimental (BGTi37). A proporção de células viáveis dos grupos controle, Ticp e BGTi37 foi estatisticamente semelhante.

A produção da fosfatase alcalina dos osteoblastos em contato com os espécimes de titânio do grupo BGTi600 foi significativamente menor do que a das células do grupo controle e do titânio microtexturizado (Ticp). A produção da fosfatase alcalina do grupo experimental BGTi600 não foi significativamente diferente quando comparada à do outro grupo experimental (BGTi37). A produção da fosfatase alcalina dos grupos controle, Ticp e BGTi37 foi estatisticamente semelhante.

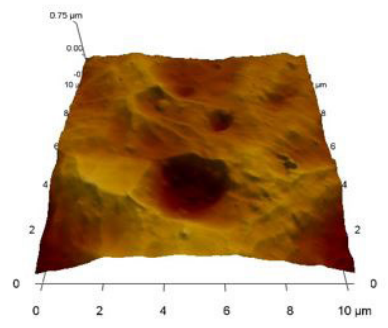

a

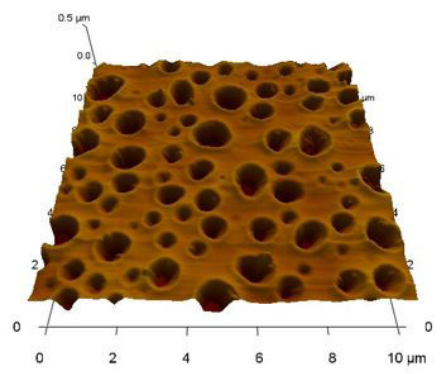

b

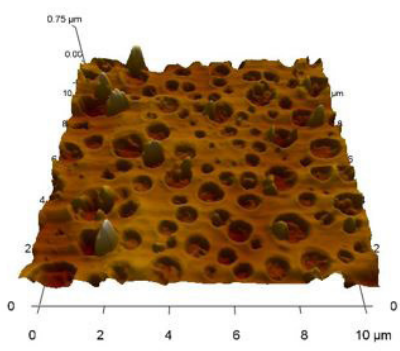

C

Figura 1. Imagens de microscopia de força atômica das superfícies, com campo de varredura de 10 micrômetros: (a) titânio puro; (b) BGTi37; (c) BGTi600. 


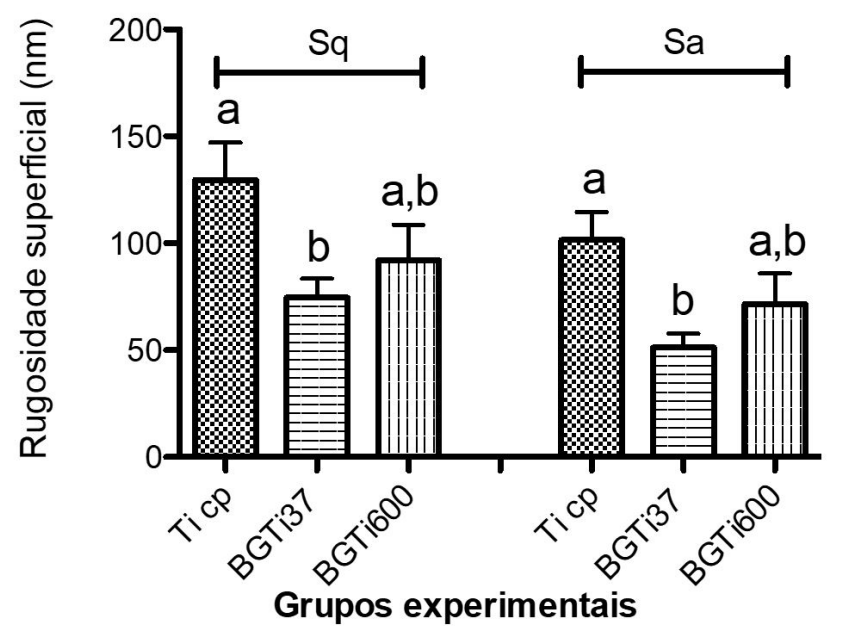

Figura 2. Rugosidade quadrática média (Sq) e rugosidade aritmética (Sa), em nanômetros, das superfícies Ticp, BGTi37 e BGTi600. Barras com as mesmas letras são estatisticamente semelhantes. Barras com letras diferentes são estatisticamente diferentes (p $>5 \%$ )(ANOVA seguido por Teste de Tukey).
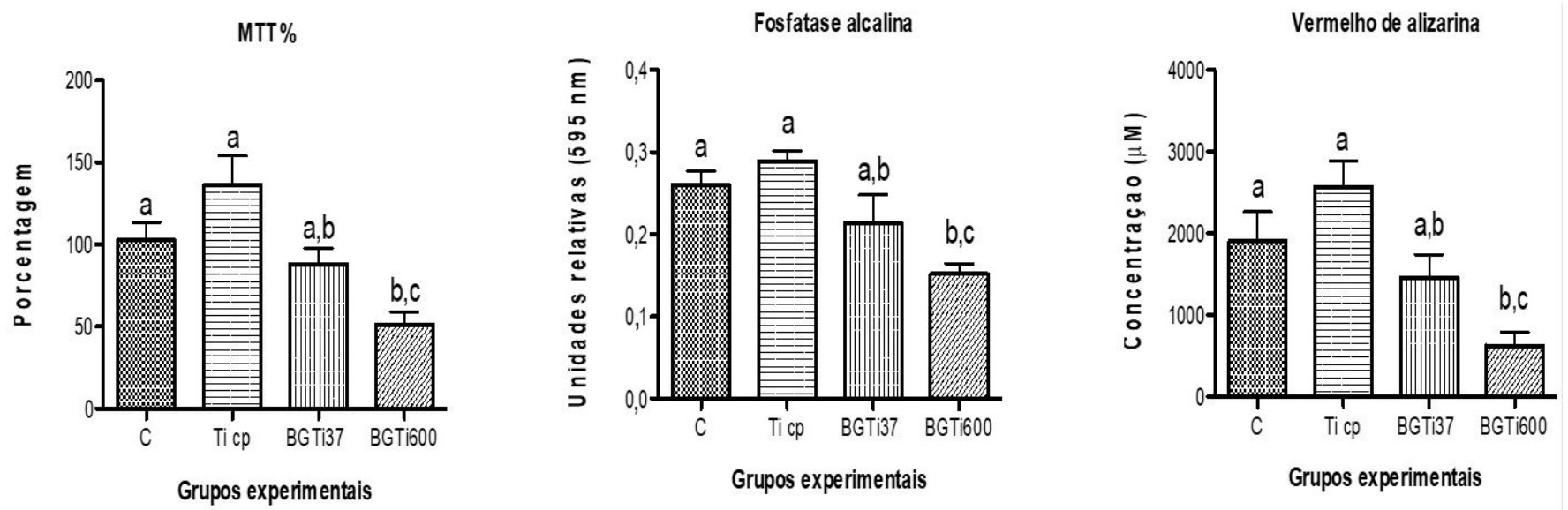

Figura 3. Viabilidade celular (MTT \%), produção de fosfatase alcalina e mineralização da matriz, por vermelho de alizarina ( $\mu \mathrm{M})$, dos osteoblastos cultivados em contato com as superfícies Ticp, BGTi37 e BGTi600. Barras com as mesmas letras são estatisticamente semelhantes. Barras com letras diferentes são estatisticamente diferentes ( $>5 \%$ ) (ANOVA seguido por Teste de Tukey).

A mineralização observada no grupo BGTi600 foi significativamente menor do que a do grupo controle e do titânio microtexturizado (Ticp). A mineralização do grupo experimental BGTi600 não foi significativamente diferente quando comparada à do outro grupo experimental (BGTi37). A mineralização dos grupos controle, Ticp e BGTi37 foi estatisticamente semelhante.

\section{DISCUSSÃO}

Diante dos resultados apresentados, a hipótese testada de que o revestimento com vidro bioativo contendo fosfato de cálcio promoveria maior ativação dos osteoblastos, quando comparado a uma superfície de Ti microtexturizada, não foi confirmada. Um dos grupos revestidos (BGTi 37) apresentou resultados estatisticamente semelhantes aos da superfície controle.

O outro grupo revestido (BGTi600) apresentou resultados piores do que a superfície controle. O fato de o grupo BGTi600 ter sido citotóxico e ter apresentado menor viabilidade celular, e consequentemente menor produção de fosfatase alcalina e mineralização, provavelmente se deve à formação e ao acúmulo de algum subproduto de cálcio após o tratamento térmico utilizado para produção dessa superfície experimental. O acúmulo de partículas extremamente solúveis poderia promover a apoptose pela incapacidade de as bombas de Ca manter as células viáveis em um meio supersaturado desse elemento químico. Essa hipótese ainda deverá ser confirmada com análises químicas das superfícies testadas.

Imagens de microscopia de força atômica também foram utilizadas para determinar a rugosidade das superfícies testadas ${ }^{6}$. Strąkowska et al. ${ }^{6}$ observaram que o revestimento de fosfato de cálcio aplicado sobre uma superfície inicialmente rugosa por jateamento e ataque ácido reduziu em, aproximadamente, $50 \%$ a rugosidade inicial. Corroborando com estes resultados, a mesma tendência à redução da rugosidade após a aplicação do revestimento com fosfato de cálcio foi observada neste trabalho. Comparando-se a rugosidade inicial com a revestida com BGTi37, observamos uma redução de aproximadamente $25 \%$. Comparando-se com a revestida com BGTi600, esta redução foi de aproximadamente $40 \%$. Apesar de terem utilizado outro método para determinar a rugosidade 
das superfícies controle e experimentais testadas em modelo animal, Lavos-Valereto et al. ${ }^{22}$ reafirmaram que a incorporação de um revestimento de hidroxiapatita, associado ou não a um vidro bioativo, sobre uma superfície jateada e tratada com ácido, resultou em diminuição da rugosidade superficial ${ }^{22}$.

Essa maior redução de rugosidade da superfície BGTi600, comparada à superfície controle e à superfície BGTi37, também pode ter contribuído para os resultados apresentados pela superfície BGTi600, a qual, sendo a menos rugosa, apresentou os piores resultados de ativação dos osteoblastos.

Revestimentos nanométricos, como o testado neste trabalho, devido às suas dimensões, podem interagir com as células de maneira mais apropriada, desempenhando um papel importante na adsorção de proteínas, na organização do citoesqueleto, na adesão e sinalização dos osteoblastos, e na osseointegração ${ }^{7,23}$. Contudo, a expressão gênica das células não foi avaliada no presente estudo, sendo portanto alvo de futuros estudos das superfícies desenvolvidas, envolvendo também células osteoprogenitoras em estágios mais precoces de diferenciação.

Os processos de adesão, proliferação e diferenciação de células osteoblásticas em contato com uma superfície experimental de titânio modificada por íons $\mathrm{Ca}^{2+}$ foram maiores do que em uma superfície de titânio sem estes íons ${ }^{24}$. Porém, a influência destes íons depende do tipo e do estágio de diferenciação celular ${ }^{25}$.

O presente trabalho não avaliou a dissociação do revestimento utilizado. Dessa forma, não foi possível afirmar qual a real dissociação do revestimento no período testado. A pouca dissociação em íons $\mathrm{Ca}^{2+}$ poderia explicar parcialmente o resultado apresentado, o que culminou com o comportamento da superfície BGTi37 semelhante ao da superfície controle microtexturizada.

Nossos resultados de viabilidade celular pelo ensaio MTT, em que somente o grupo revestido com fosfato de cálcio e seco em altas temperaturas (BGTi 600) foi citotóxico, assemelham-se aos apresentados por Pereira et al. ${ }^{5}$. Todos os grupos revestidos testados por esses autores provavelmente não sofreram nenhum tratamento térmico em altas temperaturas, já que foi adicionado a eles um peptídeo derivado do colágeno tipo I, que, para manter-se ativo, não pode ser submetido a elevadas temperaturas. Portanto, tanto nossos resultados de viabilidade celular quanto os de Pereira et al. ${ }^{5}$ demonstraram que o revestimento com fosfato de cálcio em baixa temperatura não resultou em citotoxicidade.

A viabilidade de células osteoblásticas da calvária de ratos neonatos em contato com a superfície jateada de uma liga de titânio (Ti-6Al-7Nb) e revestida com fosfato de cálcio na forma de hidroxiapatita foi menor do que a do controle, onde em que as células proliferaram na ausência de qualquer disco, nos períodos de sete e 14 dias, corroborando nossos resultados de viabilidade celular no período de sete dias. No período final de avaliação desses autores, 15 dias, a viabilidade celular foi semelhante para as superfícies revestida, não revestida e controle. Os mesmos autores observaram maior produção de matriz extracelular entre as células em contato com a superfície jateada de uma liga de titânio (Ti-6Al-7Nb) e revestida com fosfato de cálcio, na forma de hidroxiapatita ${ }^{24}$. Os dados encontrados sugerem que este contato induziu diferenciação celular mais rápida dos osteoblastos.
Os resultados de atividade da fosfatase alcalina apresentados por Pereira et al. ${ }^{5}$ e por Strąkowska et al. ${ }^{6}$ corroboram nossos resultados, sugerindo que o revestimento com fosfato de cálcio retarde a diferenciação e a ativação dos osteoblastos nas fases iniciais. Após esta iniciação, a atividade celular dos osteoblastos em contato com o revestimento de fosfato de cálcio parece aumentar em ritmo mais acelerado, o que culminou na maior mineralização observada por Pereira et al. ${ }^{5}$ após 21 dias. Klymov et al. ${ }^{7}$ também demonstraram que a concentração de cálcio nos poços contendo células só aumentou significativamente em comparação ao controle no intervalo de avaliação de 28 dias. Esta maior mineralização não foi observada em nosso trabalho, provavelmente por ter sido avaliada em período mais curto (14 dias).

Ainda que já tenham sido relatados melhores resultados de osseointegração para as superfícies rugosas ${ }^{3}$, os resultados do presente trabalho demonstraram que a diminuição da rugosidade superficial do grupo BGTi37, da ordem de $25 \%$, não diminuiu significativamente a atividade das células osteoblásticas, sugerindo que o potencial de osseointegração dessa superfície experimental seja semelhante ao da superfície microtexturizada (Ticp).

Como os revestimentos superficiais promovem simultaneamente modificação da rugosidade e da composição química superficial, ainda permanece inconclusivo se a rugosidade ou as propriedades químicas interferem mais na osseointegração e na proliferação e ativação celular.

Diferentemente de vários outros métodos de produção desses revestimentos para as superfícies de titânio, em que altas temperaturas são necessárias, o processo de produção sol-gel do revestimento testado neste estudo é menos oneroso e apresenta baixa complexidade de síntese, uma vez que tal processo pode ser realizado em temperatura ambiente, possibilitando também carrear futuramente outras substâncias biofuncionais, tais como: agentes terapêuticos, vitaminas e agentes bactericidas ${ }^{26}$. Pesquisas futuras envolvendo essa superfície testada associada a outras substâncias poderão apontar resultados superiores aos da superfície de Ti microtexturizada, promovendo-se, assim, o desenvolvimento de nova superfície com capacidade de acelerar o processo de osseointegração.

\section{CONCLUSÃO}

Apesar da sua marcante menor rugosidade, a superfície BGTi37 apresentou comportamento biológico semelhante a uma superfície de titânio microtexturizada e moderadamente rugosa (Ticp). A outra superfície experimental (BGTi600), a de menor rugosidade entre todas as testadas, apresentou os piores resultados de ativação dos osteoblastos.

\section{AGRADECIMENTOS}

Agradecemos à FAPEMIG pelos recursos disponibilizados pela agência de fomento e pelo apoio ao projeto de estudo da equipe de pesquisadores com aprovação do projeto: “Titânio com superfície modificada por biovidro: produção, caracterização química, avaliação biológica in vitro e em modelo animal" (Processo n. ${ }^{\circ}$ APQ-00542-14). 


\section{REFEREANCIAS}

1. Koller G, Cook RJ, Thompson ID, Watson TF, Di Silvio L. Surface modification of titanium implants using bioactive glasses with air abrasion technologies. J Mater Sci Mater Med. 2007 Dec;18(12):2291-6. http://dx.doi.org/10.1007/s10856-007-3137-z. PMid:17562133.

2. Surmenev RA, Surmeneva MA, Ivanova AA. Significance of calcium phosphate coatings for the enhancement of new bone osteogenesis: a review. Acta Biomater. 2014 Feb;10(2):557-79. http://dx.doi.org/10.1016/j.actbio.2013.10.036. PMid:24211734.

3. Wennerberg A, Albrektsson T. Effects of titanium surface topography on bone integration: a systematic review. Clin Oral Implants Res. 2009 Sep;20(Suppl 4):172-84. http://dx.doi.org/10.1111/j.1600-0501.2009.01775.x. PMid:19663964.

4. Knabe C, Howlett CR, Klar F, Zreiqat H. The effect of different titanium and hydroxyapatite-coated dental implant surfaces on phenotypic expression of human bone-derived cells. J Biomed Mater Res A. 2004 Oct;71(1):98-107. http://dx.doi.org/10.1002/jbm.a.30130. PMid:15368259.

5. Pereira KK, Alves OC, Novaes AB Jr, de Oliveira FS, Yi JH, Zaniquelli O, et al. Progression of osteogenic cell cultures grown on microtopographic titanium coated with calcium phosphate and functionalized with a type I collagen-derived peptide. J Periodontol. 2013 Aug;84(8):1199-210. http://dx.doi.org/10.1902/jop.2012.120072. PMid:23088527.

6. Strąkowska P, Beutner R, Gnyba M, Zielinski A, Scharnweber D. Electrochemically assisted deposition of hydroxyapatite on Ti6Al4V substrates covered by CVD diamond films: coating characterization and first cell biological results. Mater Sci Eng C. 2016 Feb;59:624-35. http://dx.doi.org/10.1016/j.msec.2015.10.063. PMid:26652416.

7. Klymov A, Song J, Cai X, Te Riet J, Leeuwenburgh S, Jansen JA, et al. Increased acellular and cellular surface mineralization induced by nanogrooves in combination with a calcium-phosphate coating. Acta Biomater. 2016 Feb;31:368-77. http://dx.doi.org/10.1016/j. actbio.2015.11.061. PMid:26691523.

8. Kokubo T, Kim HM, Kawashita M. Novel bioactive materials with different mechanical properties. Biomaterials. 2003 Jun;24(13):2161-75. http://dx.doi.org/10.1016/S0142-9612(03)00044-9. PMid:12699652.

9. Kokubo T, Takadama H. How useful is SBF in predicting in vivo bone bioactivity? Biomaterials. 2006 May;27(15):2907-15. http://dx.doi. org/10.1016/j.biomaterials.2006.01.017. PMid:16448693.

10. Vargas GE, Haro Durand LA, Cadena V, Romero M, Mesones RV, Mačković M, et al. Effect of nano-sized bioactive glass particles on the angiogenic properties of collagen based composites. J Mater Sci Mater Med. 2013 May;24(5):1261-9. http://dx.doi.org/10.1007/s10856-0134892-7. PMid:23430337.

11. Maeno S, Niki Y, Matsumoto H, Morioka H, Yatabe T, Funayama A, et al. The effect of calcium ion concentration on osteoblast viability, proliferation and differentiation in monolayer and 3D culture. Biomaterials. 2005 Aug;26(23):4847-55. http://dx.doi.org/10.1016/j. biomaterials.2005.01.006. PMid:15763264.

12. Anitua E, Prado R, Orive G, Tejero R. Effects of calcium-modified titanium implant surfaces on platelet activation, clot formation, and osseointegration. J Biomed Mater Res A. 2015 Mar;103(3):969-80. http://dx.doi.org/10.1002/jbm.a.35240. PMid:24862163.

13. Buser D, Janner SF, Wittneben JG, Brägger U, Ramseier CA, Salvi GE. 10-year survival and success rates of 511 titanium implants with a sandblasted and acid-etched surface: a retrospective study in 303 partially edentulous patients. Clin Implant Dent Relat Res. 2012 Dec;14(6):839-51. http://dx.doi.org/10.1111/j.1708-8208.2012.00456.x. PMid:22897683.

14. van Velzen FJ, Ofec R, Schulten EA, Ten Bruggenkate CM. 10-year survival rate and the incidence of peri-implant disease of 374 titanium dental implants with a SLA surface: a prospective cohort study in 177 fully and partially edentulous patients. Clin Oral Implants Res. 2015 Oct;26(10):1121-8. http://dx.doi.org/10.1111/clr.12499. PMid:25370914.

15. American Society for Testing and Materials - ASTM. ASTM B600: standard guide for descaling and cleaning titanium titanium alloy surfaces. Philadelphia: ASTM; 1997. p. 6-8.

16. Domingues RZ, Clark AE, Brennan AB. A sol-gel derived bioactive fibrous mesh. J Biomed Mater Res. 2001 Jun;55(4):468-74. http://dx.doi. org/10.1002/1097-4636(20010615)55:4<468::AID-JBM1038>3.0.CO;2-T. PMid:11288074.

17. Eaton P, West P. Atomic force microscopy. Oxford: Oxford University Press; 2010.

18. Orriss IR, Taylor SE, Arnett TR. Rat osteoblast cultures. Methods Mol Biol. 2012;816:31-41. http://dx.doi.org/10.1007/978-1-61779-415-5_3. PMid:22130920.

19. Mosmann T. Rapid colorimetric assay for cellular growth and survival: application to proliferation and cytotoxicity assays. J Immunol Methods. 1983 Dec;65(1-2):55-63. http://dx.doi.org/10.1016/0022-1759(83)90303-4. PMid:6606682.

20. Blake MS, Johnston KH, Russell-Jones GJ, Gotschlich EC. A rapid, sensitive method for detection of alkaline phosphatase-conjugated antiantibody on Western blots. Anal Biochem. 1984 Jan;136(1):175-9. http://dx.doi.org/10.1016/0003-2697(84)90320-8. PMid:6424501.

21. Lin TH, Yang RS, Tang CH, Wu MY, Fu WM. Regulation of the maturation of osteoblasts and osteoclastogenesis by glutamate. Eur J Pharmacol. 2008 Jul;589(1-3):37-44. http://dx.doi.org/10.1016/j.ejphar.2008.04.060. PMid:18538763.

22. Lavos-Valereto IC, Deboni MCZ, Azambuja N Jr, Marques MM. Evaluation of the titanium Ti-6Al-7Nb alloy with and without plasmasprayed hydroxyapatite coating on growth and viability of cultured osteoblast-like cells. J Periodontol. 2002 Aug;73(8):900-5. http://dx.doi. org/10.1902/jop.2002.73.8.900. PMid:12211500.

23. Anselme K. Osteoblast adhesion on biomaterials. Biomaterials. 2000 Apr;21(7):667-81. http://dx.doi.org/10.1016/S0142-9612(99)00242-2. PMid:10711964.

24. Xu L, Pan F, Yu G, Yang L, Zhang E, Yang K. In vitro and in vivo evaluation of the surface bioactivity of a calcium phosphate coated magnesium alloy. Biomaterials. 2009 Mar;30(8):1512-23. http://dx.doi.org/10.1016/j.biomaterials.2008.12.001. PMid:19111896. 
25. Sato M, Aslani A, Sambito MA, Kalkhoran NM, Slamovich EB, Webster TJ. Nanocrystalline hydroxyapatite/titania coatings on titanium improves osteoblast adhesion. J Biomed Mater Res A. 2008 Jan;84(1):265-72. http://dx.doi.org/10.1002/jbm.a.31469. PMid:17607739.

26. Andrade AL, Domingues RZ. Cerâmicas bioativas: estado da arte. Quim Nova. 2006;29(1):100-4. http://dx.doi.org/10.1590/S010040422006000100019.

27. De Oliveira LG. Tratamento de superfícies de titânio de grau medicinal [dissertação mestrado em Química]. Belo Horizonte: Departamento de Química da Universidade Federal de Minas Gerais; 2015.

\section{CONFLITOS DE INTERESSE}

Os autores declaram não haver conflitos de interesse.

\section{*AUTOR PARA CORRESPONDÊNCIA}

Allyson Nogueira Moreira, UFMG - Universidade Federal de Minas Gerais, Faculdade de Odontologia, Av. Pres. Antônio Carlos, 6627, 31270-901 Belo Horizonte - MG, Brasil, e-mail: dangelogatil@terra.com.br

Recebido: Maio 16, 2018

Aprovado: Julho 24, 2018 


\section{REVISTA DE ODONTOLOGIA DA UNESP}

Rev Odontol UNESP. 2018, Ahead of Print

\section{Errata}

No artigo “Avaliação topográfica e in vitro de superfícies de titânio revestidas com vidro bioativo”, DOI http://dx.doi.org/10.1590/18072577.04918, publicado no periódico Rev. Odontol. UNESP vol.47, no.4 Araraquara jul./ago. 2018, pp. 230-236, na página 231:

Onde se lê:

"Ao final desse processo, foram obtidos 21 espécimes para cada um dos dois grupos experimentais: liga de titânio grau 4 revestida com vidro bioativo contendo fosfato de cálcio e seco a $37^{\circ} \mathrm{C}$ (BGTi37) e liga de titânio grau 4 revestida com vidro bioativo contendo fosfato de cálcio e seco a $600{ }^{\circ} \mathrm{C}$ (BGTi600).”

Leia-se:

"Ao final desse processo, foram obtidos 21 espécimes para cada um dos dois grupos experimentais: liga de titânio grau 4 revestida com vidro bioativo contendo fosfato de cálcio e seco a $37^{\circ} \mathrm{C}$ (BGTi37) e liga de titânio grau 4 revestida com vidro bioativo contendo fosfato de cálcio e seco a $600{ }^{\circ} \mathrm{C}$ (BGTi600). A síntese, assim como o revestimento, foram realizados no Departamento de Química da UFMG, também descrito em De Oliveira (2015) $)^{27}$."

\section{Referência:}

27. De Oliveira LG. Tratamento de superfícies de titânio de grau medicinal [dissertação mestrado em Química]. Belo Horizonte: Departamento de Química da Universidade Federal de Minas Gerais; 2015. 